\title{
European sea bass (Dicentrarchus labrax) and meagre (Argyrosomus regius) fertilized egg resistance to a spacecraft launcher vibration qualifying test
}

\author{
C. Przybyla ${ }^{1}$ (D) - G. Dutto ${ }^{2}$ - M. Bernard ${ }^{3}$ B. Bollin ${ }^{2} \cdot$ X. Laurand ${ }^{3} \cdot$ J. Averseng $^{4}$. \\ E. Gasset ${ }^{1} \cdot$ I. Tadadjeu ${ }^{3} \cdot$ L. Dusseau ${ }^{3}$
}

1 MARBEC, CNRS, IFREMER, IRD, Univ. Montpellier, Palavas-les-Flots, France

2 French Research Institute for Exploitation of the Sea (Ifremer), Laboratoire L-sea, Chemin de Maguelone, Palavas-les-Flots, France

3 Montpellier University Space Centre (CSUM), University Montpellier, Montpellier, France

4 Laboratory of Mechanics and Civil Engineering (LMGC) UMR 5508, University Montpellier/CNRS, Montpellier, France

\begin{abstract}
Food autonomy represents an essential challenge for the future Moon Village planned by the European Space Agency. Rearing fish on the moon to provide essential amino acids, omega-3 polyunsaturated fatty acids and vitamin $\mathrm{B}_{12}$ could become a reality using integrated multi-trophic aquaculture (IMTA). The Lunar Hatch programme's goal is to fertilize farmed fish eggs on Earth that would hatch upon arrival at the lunar base. However, the vibrations from a spacecraft's launch are an unusual situation for fish eggs and may have a negative impact on them. European sea bass (Dicentrarchus labrax) and meagre (Argyrosomus regius) eggs were exposed to mechanical stresses using standard protocol performed to approve a satellite for space launch. The hatching rate was evaluated after vibration expositions at different hours post fertilization (hpf). An initial series of tests subjecting the eggs to orbital rotation demonstrated their integrity. In subsequent tests, mechanical stressors acting on the Soyuz spacecraft was simulated to test impact on fish eggs. The results showed egg robustness for European sea bass at $35 \mathrm{hpf}$ (one-third of the embryo development) and $83 \mathrm{hpf}$ (two thirds) and of meagre at $14 \mathrm{hpf}$ (one third), with no significant difference in hatching rate compared with an unshaken control batch. European sea bass embryos and potentially other fish species with similar incubation periods (4-6 days) seem to be good candidates to surviving a spacecraft launch. This paper discusses the findings and suggests possible future research avenues.
\end{abstract}

Keywords Aquaculture $\cdot$ Space flight $\cdot$ Fish eggs $\cdot$ Embryogenesis $\cdot$ Food autonomy $\cdot$ Biological life support system $\cdot$ Moon 


\section{Introduction}

In recent years, several space agencies have begun ambitious projects to establish a long-term manned base on the Moon. Regardless of which solution is selected, one of the main challenges for a lunar outpost will be food autonomy. Launching a cargo of fresh or lyophilized food into space daily is not a viable option from a technical or economic point of view. One answer lies in developing a bioregenerative life support system (BLSS) that includes a waste recycling-based food supply.

Most BLSS research has focused on cultivating bacteria (Leys et al. 2009) and photosynthetic organisms in space (Poulet et al. 2016) using a closed loop based on waste recycling, $\mathrm{CO}_{2}$ removal and oxygen production (Poughon et al. 2009). In earlier studies, a small number of higher plants were tested in space on the Salyut, Mir and International Space Stations (Salisbury and Clark 1996), including lettuce, tomatoes, wheat and soybeans (Zabel et al. 2016). More recently, microalgae, another photosynthetic organism, have been cultivated in BLSS research (Niederwieser et al. 2018a). The green algae Chlorella vulgaris in particular seems to be a promising candidate for an aquatic food loop (Niederwieser et al. 2018b). However, food sources based solely on the fruits and vegetables that have been studied for space systems do not cover all human dietary requirements (Lane et al. 2013).

The recent discovery of hydroxyl and forms of water on the Moon has revived the idea of space aquaculture (Mitrofanov et al. 2016; Nurge 2012; Siegler et al. 2015). Aquatic organisms could help to fill this gap. Fish could provide adequate amino acids to decrease muscle loss on long-duration flights (Stein and Blanc 2011) and supply important lipids such as omega-3 fatty acids, including EPA and DHA (Arthur 2009), which are vital compounds for human cerebral functions (Ghasemi Fard et al. 2019). Another advantage - in contrast to farmed poultry and mammals, for example - is that aquatic organisms are protected by water, which is an intrinsic radiation shield. A water layer can mitigate the effects of charged particles (Baiocco et al. 2018); one study has shown that a human spacesuit made only of water can reduce exposure to solar protons by as much as 50\% (Vuolo et al. 2017). Additionally, due to their physiology, fish require five to twenty times less energy than mammals, around three times less oxygen, and generate less carbon dioxide emissions (Gonzales 2009). Lastly, the feed conversion ratio of aquatic organisms is better than that of terrestrially farmed animals (Tacon and Metian 2008; Zuidhof et al. 2014), so relying on the latter would limit food production and autonomy on a future lunar base.

\section{Space multi-trophic aquaculture potential}

By exploring the possibilities of synergy between ecological research in a closed system developed on Earth and the challenges of the solar system exploration, integrated aquaculture seems to offer a stimulating subject which can also have practical rewards in the short term (Hanson 1983). For all these reasons, fish aquaculture in space, in addition to cultivating photosynthetic organisms, could be a valuable source of fresh food for lunar crews. In the framework of sustainable aquaculture on Earth, these two types of food production are already considered complementary (Brown et al. 2011; Li et al. 2019; Mladineo et al. 2010). Researchers are studying trophic cascades that reuse fish effluent (nutrients excreted from fish) to feed cultured microalgae. The algae in turn play a role in water depuration and can be a feed source for farmed fish (Dallaire et al. 2007; Tulli et al. 2012). This produces a semi-closed loop in which the by-products from one aquatic system are used as the inputs for another, 
called an integrated multi-trophic aquaculture (IMTA) system. While advanced research has been done on cultivating higher plants in space, fish cultivation in space (Blum et al. 1995) could be deepened with current IMTA knowledge gathered on Earth, which has shown that feeding fish with fresh, moist food (i.e. wet algae) does not alter fish growth performance and stimulates immune response (Przybyla et al. 2014). Theoretically, fish could be partially fed using fresh microalgae cultivated in space.

The aim of the Lunar Hatch programme is to develop a method to send embryonated fish eggs in space and to programme their hatching in an IMTA system on the Moon. There, the larvae and fish will be reared until they reach an appropriate weight for human consumption. The choice of eggs as the biological stage for a spaceflight has a number of advantages. A low volume of water is required for egg incubation, so the initial payload could be less than $1 \mathrm{~kg}$ for 900 future adult fish. Egg density in the water column is around one egg per millilitre and depends on the fish species. Unlike the larval or adult stages, the embryogenesis phase is suitable for a space flight because embryo development does not require human intervention for several days (the timing also depends on the species). This would allow either long manned spaceflights with no need for maintenance of the eggs or simply sending them on unmanned spacecraft as cargo.

\section{Eggs in space}

If study on vertebrate embryos in space is poorly documented, very few studies on fertilized fish eggs in conditions of microgravity and data using aquaculture fish eggs are available.

In 1973, the Skylab 3 mission boarded 50 fertilized eggs of the mud minnow (Fundulus heteroclitus), a small saltmarsh fish, as well as several juvenile specimens. Astronauts found 48 larvae from this wild species, by their third week on the space station, a hatching rate of 96\% (Johnson 2016).

In February 1979, the first avian eggs (Japanese quail) were boarded onto Soyuz 32 to join the Inkubator-1 module on the Russian space station Salyut 6. The aim was to study the impacts of zero-gravity environments on the development of embryos - and on the lifecycle as a whole - in the framework of finding prospective food sources for future cosmonauts. While the quail eggs hatched on Salyut 6, the development of the quail embryos progressed more slowly than in a terrestrial context, and after hatching, some quail chicks were acephalous. Later, vital organs were also studied on boarded embryos on the MIR station (Barrett et al. 2000).

In 1994, aboard a space shuttle in the International Microgravity Laboratory (IML-2), 43 eggs of the medaka (Oryzias latipes), an ornamental fish, were fertilized in space, from which 8 fry hatched. The unhatched eggs were then sent back to Earth, and a further 30 fry hatched within 3 days of landing (Ijiri 1998).

In 2007, the Biorisk experiment exposed fresh water killifish (Nothobranchius guentheri) eggs to the outer side of the Russian Segment of the International Space Station (ISS) for 1 month. This species is an ornamental fish with the unusual characteristic that it produces eggs that incubate in dry conditions. Unfortunately, the extreme heat deformed the plastic petri dishes and the samples kept in cotton bags were unexploited (Baranov 2009).

As a precondition to planning a BLSS that integrates IMTA for the moon station, several biological questions have to be studied concerning the aquatic organism's trip to reach the moon base. This paper focuses on the first effects applied to fish embryos during the space launch phase: the mechanical and acoustic vibrations. 


\section{The experimental fish species choice}

To date, several space missions have tracked water presence on the Moon and Mars. The water quality is not clearly known. Recent discoveries have reported the presence of water on the moon in the form of ice or hydroxyls in the lunar regolith (Basilevsky et al. 2012). The next lunar missions will prospect for ice water or underground water probably mineralized by geologic processes. The diversity of fish species allows two possible candidates: fresh or saltwater species. If water is produced by hydroxyl combination, then freshwater aquaculture species are good candidates (Gonzales and Brown 2006). If moon water or moon ice is mineralized due to geological and chemical interactions over several billions of years, or wasted salt water from the hydrogen extraction process (electrolysis) can be reused, osmoregulating aquaculture fish (the marine profile) would be the best candidates. Authors made the choice to study marine fish, with the idea that the solar system provides at least an example of a celestial body with a high quantity of mineralized water ...the Earth. It might be possible elsewhere.

The United Nation Food and Agriculture Organization lists 360 fish species used for aquaculture around the world (FAO 2018). A preliminary study based on a bibliographic work has selected around 22 aquaculture fish potentially as candidates (marine, brackish and fresh water) for a moon flight, focussing on the knowledge of its embryonic stage oxygen needs, carbon dioxide production, embryogenesis duration and charged particle resistance (publication in preparation). The European sea bass (Dicentrachus labrax) appears in this list with other marine and freshwater fish.

The meagre (Argyrosomus regius) has an embryonic development three times faster than the European sea bass. It is an excellent biologic support for evaluating if a relationship exists between embryo development speed and resistance to vibration exposure.

Our project (Launch Vibrations on Fish Embryos LAUVE) investigated the influence of launcher vibrations on the embryogenesis of two fish species that are widely used in aquaculture, with two different egg development strategies: the European sea bass and the meagre.

As well as testing the influence of launcher vibrations, we also sought to determine which embryo stage would be most able to withstand these vibrations. This was defined by the hours post fertilization (hpf) of the egg.

A preliminary experiment was conducted in which European sea bass eggs were shaken in orbital rotation to evaluate their behaviour in response to an unusual intense vibration. These experiments also helped to validate the design of the experimental module for the subsequent experiment. In the second experiment, triplicate samples of European sea bass and meagre eggs at different hours post fertilization were subjected to a simulated Soyuz takeoff using the classical protocol for satellite qualification for space launch.

\section{Materials and methods}

\section{Experimental tank}

For the experiment, the Ifremer team designed a closed, impervious experimental tank to be inserted in the CubeSat nanosatellite. Called the LAUVE CubeSat (LCS), the tank was made from polyvinyl chloride and could hold $230 \mathrm{ml}$ of seawater. To avoid destructive shocks from the eggs hitting the tank walls, the interior has no angles and has a shape similar to a halfsphere (Fig. 1). The LCS tank diameter was $6.4 \mathrm{~cm}$, with a full weight of $639 \mathrm{~g}$ when carrying the payload of $230 \mathrm{ml}$ of water and 200 eggs (Fig. 2). The entire volume of the LCS was filled 

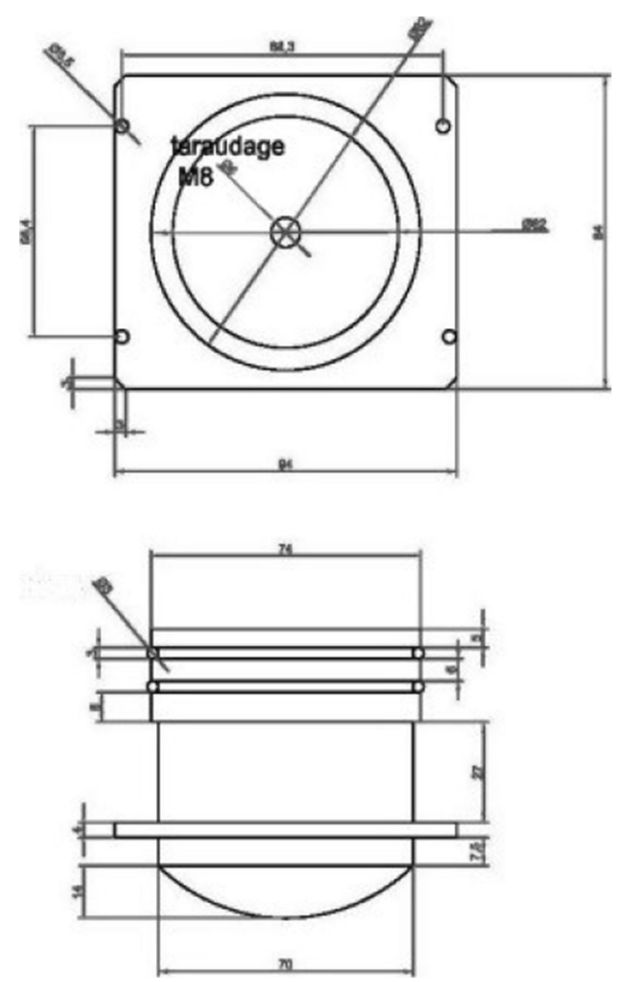

Fig. 1 Lauve CubeSat (LCS) cross section

with seawater. Particular attention was given to avoid a gaseous bubble of air above the water, as wave movement inside the LCS module during vibration tests was liable to degas the dissolved oxygen from the water column, thus jeopardizing egg survival.

\section{Biological material}

For the preliminary orbital rotation experiment, eggs were produced at the Ifremer aquaculture station (in Palavas-les-Flots, France) from European sea bass brood stock. Until the vibration tests, 2000 floating eggs from a controlled spawn and fertilization were isolated in a recirculating aquaculture system (RAS) with seawater maintained at $15.0^{\circ} \mathrm{C}$.

For the subsequent Soyuz mechanical tests, the European sea bass and meagre eggs came from a natural spawn at a local fish farm close to the Ifremer laboratory. Spawn was maintained in an RAS at around $13.0^{\circ} \mathrm{C}$ for the European sea bass eggs $(n=2000)$ and at $18.0^{\circ} \mathrm{C}$ for the meagre eggs $(n=2000)$ before selection for the experiment.

\section{Egg sample preparation}

Fertilized eggs of the European sea bass and the meagre are transparent. The first cellular divisions and the start of the embryo form are easily visible without a clarifier agent. Due to the possibility of the presence of unfertilized eggs (size $1 \mathrm{~mm}$ ), or eggs 
that stopped cellular division in the spawn, a volume of eggs were sampled from the incubator for fertilization evaluation using a binocular microscope (Motic-w10x20) and a small grid tank originally used for algae or zooplankton counting. Only eggs with an embryo primary form along the chorion (a dark curved shadow) were chosen for the experiment in order to be sure viable embryonated eggs were selected, insuring the robustness of the sample. Thus, the earliest embryonic stage tested in the study was after $30 \mathrm{hpf}$ for the European sea bass and $14 \mathrm{hpf}$ for the meagre which represent one-third of the development of the two species. Parameters and water conditions for the different experiments are presented in Table 1.

\section{Orbital rotation experiment}

The aim of the orbital rotation test was both to validate the design of the LSC experimental module and to test the eggs' capacity to withstand harsh vibration stress at different embryonic stages. The egg samples at $56 \mathrm{hpf}$ and $71 \mathrm{hpf}(n=200)$ were manually counted and embryo presence was checked visually. As in the previous protocol, all selected eggs from the experimental samples were embryonated. Two samples were placed in 250-ml glass beakers (filled to $230 \mathrm{ml}$ ) and the third sample was locked in the LCS $(230 \mathrm{ml})$. An orbital shaker (Edmund Bühler KS-15) applied $250 \mathrm{rpm}$ for $15 \mathrm{~min}$ on the LCS and one of the beakers firmly attached to the device. The non-shaken glass beaker (used as a control) was placed far from the trial site to avoid possible vibrations. After the rotation phase, the three samples were individually placed in aerated $230-\mathrm{ml}$ glass beakers and left to float in a cylinder-conical incubator at $14.6 \pm 1.8{ }^{\circ} \mathrm{C}$ with a salinity level of $37.8 \mathrm{PSU}$ until the end of embryonic development and hatching.

\section{Soyuz mechanical test}

The Soyuz launch system was selected because this launcher model is used for classical testing to qualify satellites and microsatellites for space flight. Vibration levels will never

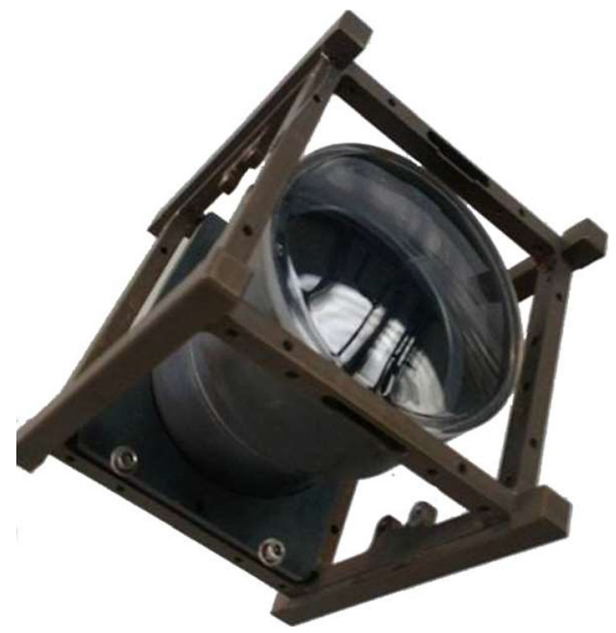

Fig. 2 The Lauve CubeSat (LCS) experimental module 
be higher than Soyuz. The objective of the simulation was to apply random vibrations, imitating reality. Originally, this vibration test is required for boarded electronics on a space mission. The experiment originality is that boarded devices and machines were replaced by fertilized eggs which will undergo the same qualification test. A vibration exciter (B\&K $4801+4812$ ) from the University of Montpellier's Laboratory of Mechanics and Civil Engineering was used to mimic launch vibration environments. The SOYUZ-2/FREGAT flight environment was numerically programmed into the vibration exciter and piloted in an open loop using an HP 3562A dynamic signal analyser with one signal for generation and two for measurement. A metallic box was specially designed to hold the LCS module. Accelerations were recorded using microprobes applied to the top and the centre of the box containing the LCS. Before each round, the vibration exciter was calibrated. Random vibration accelerations were divided into two launch phases: a first phase of $120 \mathrm{~s}$ corresponding to the launcher boosters' mechanical vibrations at ignition and lift-off (acceleration power density: $0.02 g^{2} / \mathrm{Hz}$ on a $20-300-\mathrm{Hz}$ band), and a second phase of $480 \mathrm{~s}$ in which acoustic waves appear due to the increased speed of the launcher (acceleration power density: $0.05 \mathrm{~g}^{2} / \mathrm{Hz}$ on a $100-1000-\mathrm{Hz}$ band). The frequency and spectral density of vibrations at qualification levels are described in Table 2. After $600 \mathrm{~s}$, the spaceship was considered in low orbit (Kàrmàn line around $100 \mathrm{~km}$ ), thruster action decreased and acoustic vibrations stopped. The total time for a complete experiment (set, calibration, test, dismantling) was around $1 \mathrm{~h}$ for the entire triplicate.

\section{Egg samples in the Soyuz experiment}

As in the initial orbital rotation experiment, the samples for the Soyuz test were in triplicate ( $n=200 / \mathrm{LCS}$ ), with the eggs counted manually and the embryo presence checked visually. For the European sea bass, two embryo stages were tested at $35 \mathrm{hpf}$ and $83 \mathrm{hpf}$. The incubation water temperature in the European sea bass experiment was $13.1{ }^{\circ} \mathrm{C}$, while in the meagre experiment, it was $18.0{ }^{\circ} \mathrm{C}$. The higher temperature for the meagre was due to the specific comfort zone for this species. These temperatures are commonly applied in industrial

Table 1 Embryonic stage exposed and environmental parameters along the experimentation (NA, not available)

\begin{tabular}{|c|c|c|c|c|c|c|}
\hline & & \multicolumn{4}{|c|}{ European seabass } & Meagre \\
\hline & & \multicolumn{2}{|c|}{$\begin{array}{c}\text { Orbital rotation } \\
250 \mathrm{t} / \mathrm{mn} \\
\end{array}$} & \multicolumn{3}{|c|}{ Soyuz qualification test } \\
\hline & Embryonic stage exposed (hpf) & 56 & 71 & 35 & 83 & 14 \\
\hline & $\begin{array}{l}\text { Percentage of embryo } \\
\text { development }\end{array}$ & $60 \%$ & $76 \%$ & $32 \%$ & $75 \%$ & $38 \%$ \\
\hline & Vibration duration (s) & 600 & 600 & 600 & 600 & 600 \\
\hline Spawning tank & Water temperature $\left({ }^{\circ} \mathrm{C}\right)$ & $15.0^{ \pm 0.2}$ & $14.9^{ \pm 0.2}$ & $13.2^{ \pm 0.1}$ & $13.0^{ \pm 0.4}$ & $13.1^{ \pm 0.1}$ \\
\hline \multirow{3}{*}{$\begin{array}{l}\text { LAUVE } \\
\text { Cube-Sat } \\
\text { (LCS) } \\
\text { Module }\end{array}$} & Water temperature $\left({ }^{\circ} \mathrm{C}\right)$ & 14.8 & 14.6 & 13.6 & 13.4 & 18 \\
\hline & $\begin{array}{l}\text { Water oxygen concentration } \\
\left(\mathrm{mg} \cdot \mathrm{L}^{-1}\right)\end{array}$ & 7.9 & NA & 21.5 & 27.5 & 15.0 \\
\hline & Water oxygen (\% saturation) & 99 & NA & 260 & 335 & $<200$ \\
\hline \multirow{3}{*}{ Incubator } & Water temperature $\left({ }^{\circ} \mathrm{C}\right)$ & $14.6^{ \pm 1.8}$ & 15 & 13.2 & 13.3 & 18 \\
\hline & Water salinity (PSU) & 37.8 & 37.8 & 37.8 & 37.7 & 37.6 \\
\hline & Hatching time (hpf) & 94 & 94 & 110 & 110 & 37 \\
\hline
\end{tabular}


aquaculture (Mylonas et al. 2013). As the testing facility was located $17 \mathrm{~km}$ from the marine biology station (around $30 \mathrm{~min}$ by car), both triplicates (LCS and control) were transported by car to ensure the same handling constraints. The simulation experiment was carried out only on LCS samples, not on the control. After vibration exposition LCS and control triplicates went back into a classical incubator in RAS. The experimental design is summarized in Fig. 3. A short previous experiment showed that the oxygen quantity dissolved into a 230 -ml closed volume was sufficient for 200 eggs' physiology for a residence time in the LCS module less than $8 \mathrm{~h}$. For the Soyuz experiment, embryos were closed for around 3 hours.

\section{Hatching rate evaluation}

For both the orbital rotation and spatial qualification tests, the hatching evaluation protocol was the same. For both species, after the theoretical date of hatching, each sample was filtered with a 700- $\mu \mathrm{m}$ mesh and visually analyzed to detect young larvae using the same binocular microscope described previously. For the orbital rotation experiment, the number of live larvae was recorded and results were given in the percentage of live larvae:

$$
\text { Hatching rate }(\%)=\frac{\text { Live larvae }}{\text { Sample size }}
$$

The orbital experiment showed that some embryos considered dead were in fact alive in the egg envelope but unhatched. Thus, other biological information in addition to live larvae was collected in the Soyuz experiment. Eggs were identified as dead (embryo development process definitely stopped) by their dark colour, while unhatched eggs were identified by their translucent aspect and the presence of the embryo. This information was recorded for the experiments with European sea bass at $35 \mathrm{hpf}$ and meagre at $14 \mathrm{hpf}$, and the hatching rate calculation was modified to:

$$
\text { Hatching rate }(\%)=\frac{\text { Live larvae }}{(\text { Live larvae }+ \text { dead }+ \text { unhatched })}
$$

\section{Statistics}

For each test (orbital rotation and Soyuz simulation), the hatching rate as a percentage ( $p$ ) was converted using $x=\sqrt[2]{\arcsin (p)}$. Transformed data was tested for normality and equal variance. All the dataset profiles allowed the parametric $t$ test to be used.

\begin{tabular}{|c|c|c|c|c|c|c|c|c|}
\hline \multirow[b]{2}{*}{$\begin{array}{l}\text { Operational } \\
\text { phase }\end{array}$} & \multicolumn{7}{|c|}{ Frequency sub-band, $\mathrm{Hz}$} & \multirow[b]{2}{*}{$\begin{array}{l}\text { Acceleration } \\
\text { in } \mathrm{g}\end{array}$} \\
\hline & $\begin{array}{c}\text { Duration } \\
\text { (sec) }\end{array}$ & $\begin{array}{c}20- \\
50\end{array}$ & $\begin{array}{l}50- \\
100\end{array}$ & $\begin{array}{l}100- \\
200\end{array}$ & $\begin{array}{c}200- \\
500\end{array}$ & $\begin{array}{l}500- \\
1000\end{array}$ & $\begin{array}{l}1000- \\
2000\end{array}$ & \\
\hline \multirow{3}{*}{$\begin{array}{l}\text { Vehicle } \\
\text { launch }\end{array}$} & \multicolumn{7}{|c|}{ Spectral density $\mathrm{g}^{2} / \mathrm{Hz}$} & \\
\hline & 120 & 0.02 & 0.02 & $\begin{array}{c}0.02- \\
0.05\end{array}$ & 0.05 & $\begin{array}{l}0.05- \\
0.025\end{array}$ & $\begin{array}{c}0.025- \\
0.013\end{array}$ & 7.42 \\
\hline & 480 & 0.02 & 0.02 & 0.02 & $\begin{array}{l}0.02- \\
0.008\end{array}$ & $\begin{array}{c}0.008- \\
0.004\end{array}$ & $\begin{array}{c}0.004 \\
0.002\end{array}$ & 3.54 \\
\hline
\end{tabular}

Table 2 Random vibration parameters for flight qualification levels 


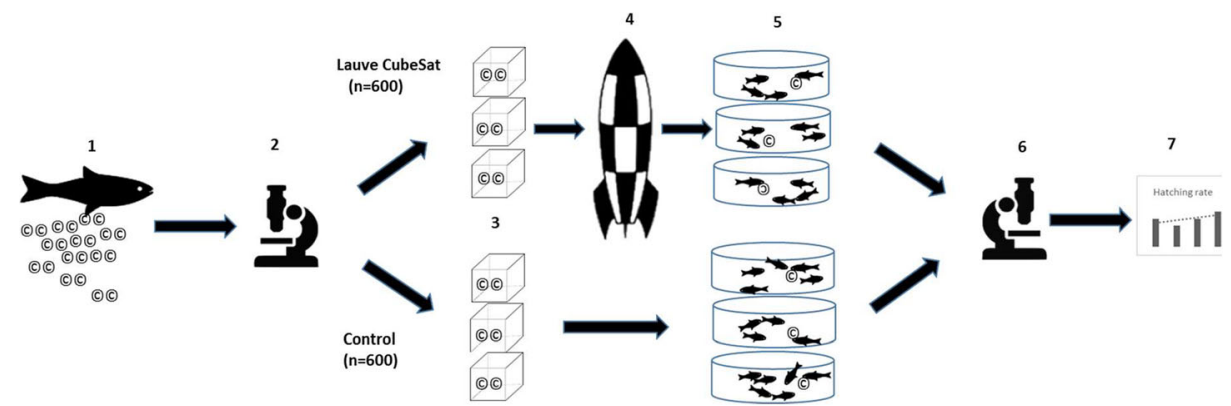

Fig. 3 The experimental design of the Soyuz vibration simulation. (1) Fertilization of 2000 eggs of the studied species. (2) Visual check for embryo presence. (3) Two hundred eggs per module tested in triplicate. (4) LCS submitted to simulated Soyuz mechanical and acoustic vibrations. (5) Standard rearing conditions in tank for all samples until hatching. (6) Visual check for live larvae and dead or unhatched eggs. (7) Evaluation of hatching rate depending on conditions

\section{Results}

\section{Orbital rotation}

In this test, European sea bass eggs at $56 \mathrm{hpf}$ and $71 \mathrm{hpf}$ were shaken for $15 \mathrm{~min}$ at $250 \mathrm{rpm}$. No leaks were observed in the LCS module. The eggs were in rotation in the rotation direction of the device and were distributed equally in the water column along the wall of the LCS or beaker. The 56-hpf eggs hatched $40 \mathrm{~h}$ after the test and the 71-hpf eggs after $22 \mathrm{~h}$, corresponding to a simulated launch at $60 \%$ and $76 \%$ of embryonic development respectively. When the LCS module was opened, the eggs were in good condition: no egg envelope detritus was observed. After a period of incubation in a standard closed-system aquaculture environment, live larvae were visually counted for each sample: LCS, open beaker and the control. The results are presented in Fig. 4.

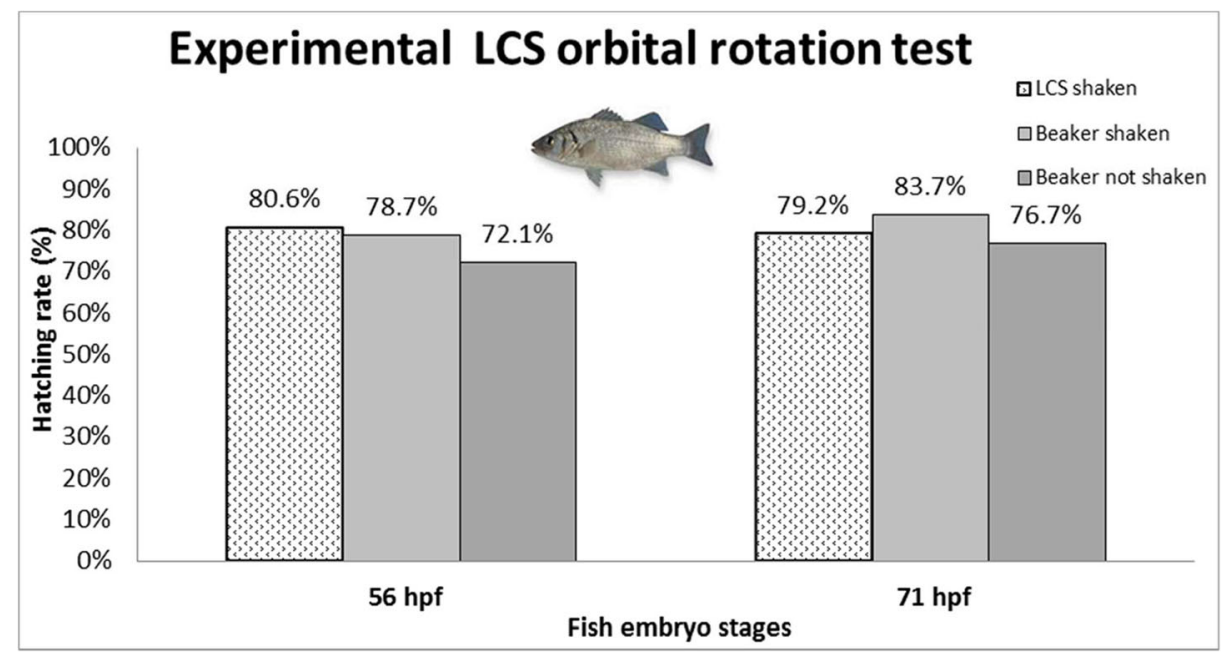

Fig. 4 Pilot study results: European sea bass hatching rate after orbital rotation ( $250 \mathrm{rpm}-10 \mathrm{~min})$ on embryo stages at $56 \mathrm{hpf}$ and $71 \mathrm{hpf}$. Testing conditions: shaken LCS module, shaken beaker and a beaker control that was not shaken 
The European sea bass hatching rates were between 72.1 and $83.7 \%$ for the three samples. This range can be considered normal, falling in the high range of the hatching rate in commercial conditions. The overall structure of the LCS and its mounting on the CubeSat preserved the eggs' integrity during the multidirectional forces applied in orbital rotation. These positive results allowed us to move on to the Sine-on-Random vibration experiments simulating a Soyuz launch.

\section{Soyuz mechanical test}

\section{European sea bass}

For European sea bass eggs subjected to vibrations at $35 \mathrm{hpf}$ and $83 \mathrm{hpf}$, hatching was observed at $110 \mathrm{hpf}$ for both, despite the fact the eggs came from different fertilization batches. As a result, we can retrospectively calculate that launch simulation occurred at $32 \%$ and $75 \%$ of embryonic development, respectively. Random vibrations did not affect fish egg integrity.

The hatching rate was $75.8 \% \pm 4.0$ for samples tested in the LCS and $82.1 \pm 3.5$ for control samples. In terms of residual biological materials, LCS samples revealed that $21.8 \% \pm 4.4$ of the eggs were dead and $2.6 \% \pm 0.5$ were unhatched, while in the control samples, $17.5 \% \pm 3.2$ of eggs were dead and $1.8 \% \pm 0.7$ were unhatched. No significant difference was observed for these parameters.

In the latest embryonic stage ( $83 \mathrm{hpf}$ ), the hatching rate was $92.9 \% \pm 1.8$ for LCS samples and $96.7 \% \pm 2.4$ for control samples. Respectively, $7.1 \% \pm 1.8$ and $4.1 \% \pm 2.0$ were considered unhatched eggs (including dead eggs) because visual differentiation was not possible. No significant difference was observed for these parameters. The results are presented in Fig. 5.

\section{Meagre}

In meagre, the period of incubation is physiologically shorter than that of European sea bass. For the Soyuz test on eggs at $14 \mathrm{hpf}$, the hatching time was observed at $37 \mathrm{hpf}$. At the moment

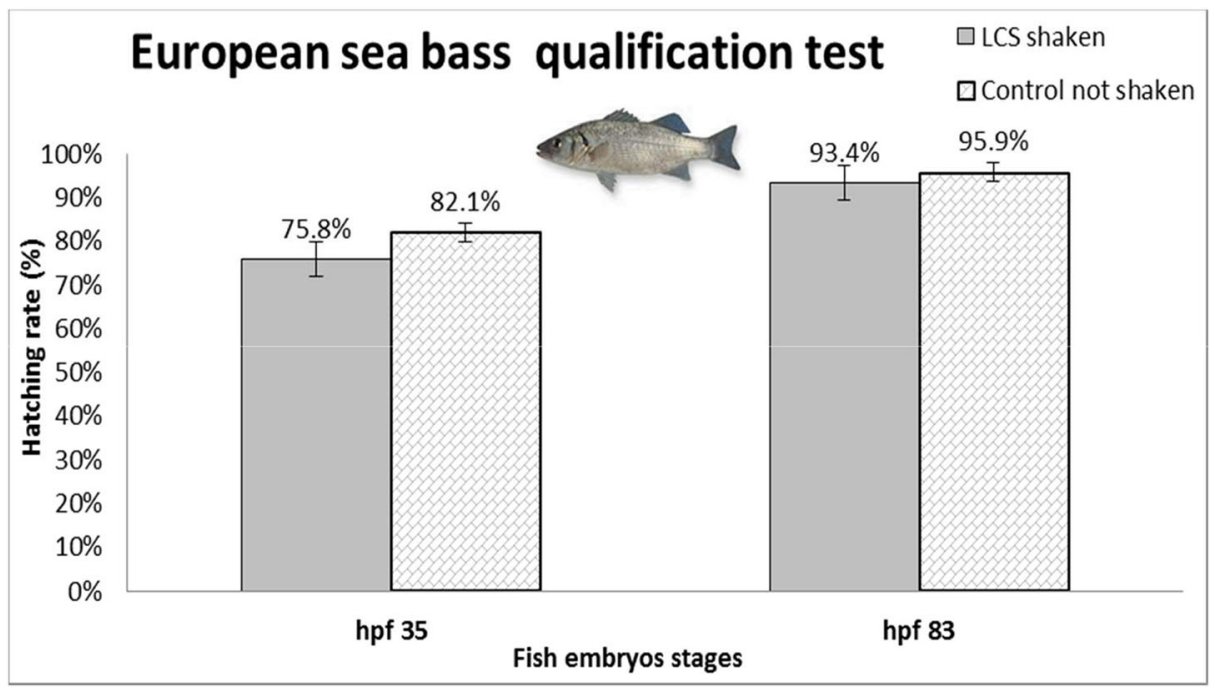

Fig. 5 European sea bass hatching rate after Soyuz launch simulation (standard qualification test-10 min) on embryos at $35 \mathrm{hpf}$ and $83 \mathrm{hpf}$ for the testing conditions in triplicate: shaken LCS module and a control LCS that was not shaken 


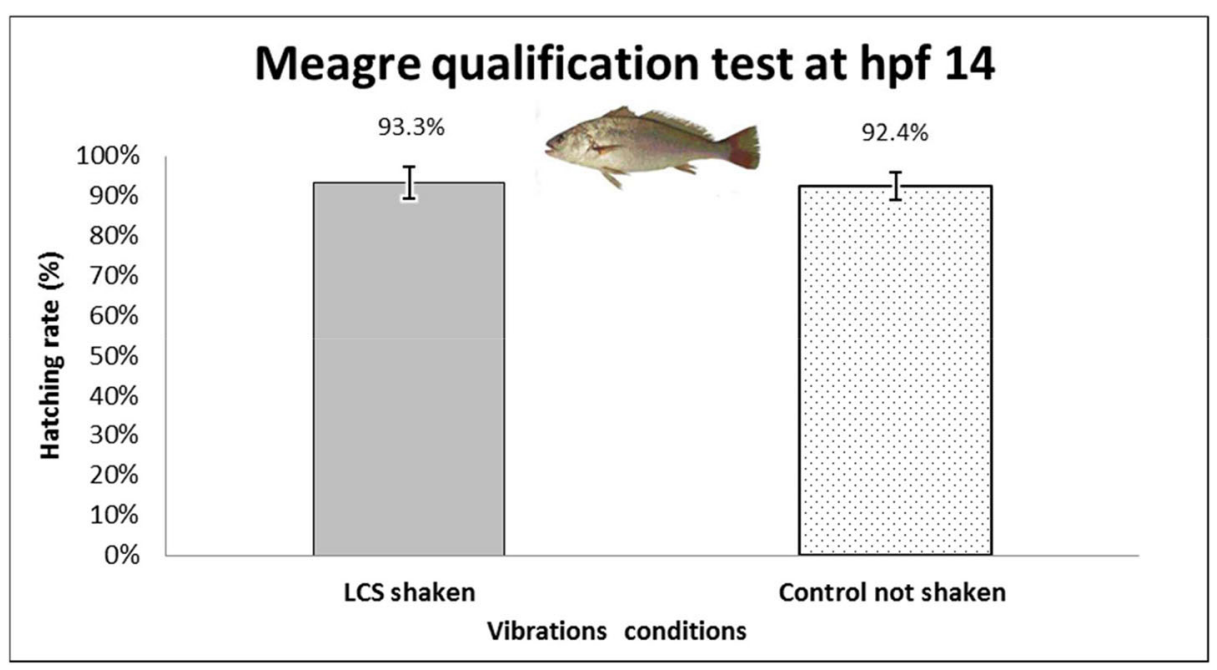

Fig. 6 Meagre hatching rate after Soyuz launch simulation (standard qualification test - 10 min) on embryos at $14 \mathrm{hpf}$ for the two testing conditions in triplicate: shaken LCS module and a control LCS that was not shake

of exposure to launch vibrations, the embryonic development was at $38 \%$. The hatching rate is presented in Fig. 6.

The meagre hatching rate was $95.3 \% \pm 6.3$ for samples tested in the LCS and $92.4 \% \pm 6.2$ for control samples. In terms of residual biological materials, LCS samples revealed that $6.3 \%$ \pm 4.1 of the eggs were dead and $2.6 \% \pm 0.5$ were unhatched, while in the control samples, $6.4 \% \pm 5.2$ of the eggs were dead and $1.8 \% \pm 0.8$ were unhatched. No significant difference was observed for these parameters.

\section{Discussion}

Marine organisms and fish were the first forms of life on Earth in the prehistoric stormy oceans (Quinton 1912). Fish reproductive strategy selected for embryonic eggs capable of surviving turbulent stream forces. Regardless of the species, embryo stage or embryo physiology, our results demonstrated that fish eggs show good robustness to withstanding launcher vibrations. These results could be explained by the natural embryo protection to extreme conditions. In contrary to poultry eggs or mammalian embryos, fish eggs in the open sea are subject to harsh movements in random directions. Fish embryos are protected by the chorion from mechanical stresses such as shocks and acoustic vibrations. The chorion $(3-4 \mu \mathrm{m})$ is a cellular envelope surrounding the mature eggs of teleost fish and is composed of several protective layers of specific glycol-proteins. This structure plays a role in immunogen production during incubation (Scapigliati et al. 1994) as chorion glycoproteins are synthesized in the genitor's livers (Saavedra et al. 2016). In the context of a space aquaculture programme, brood stock management must stay on the Earth which optimizes brood stock feed quality in the aim of maintaining chorion quality.

The Skylab 3 mission, in 1973 with mud minnow (Fundulus heteroclitus), recorded a hatching rate of $96 \%$ (Johnson 2016) and $86 \%$ on zebrafish (Orysias latipes) in the International Microgravity Laboratory mission in 1994 (Ijiri 1998). While the mud minnow and the zebrafish are not aquaculture species, these hatching rates in space are close to the meagre in our study. It confirms 
that the earlier stage of development is most relevant for a space flight. In contrast to the juvenile fish, fish fry never displayed space sickness behaviour, detected by loop swimming (Baumgarten 1975; Chatani et al. 2015). The absence of space sickness may be associated with the fact that the otoliths are not totally formed during the embryogenesis, so it has a low impact (Chatani et al. 2015; Ijiri et al. 2003). The start of otolith development in space and the protection afforded by the chorion could contribute to an easy acclimation to microgravity during embryo formation.

Our study indicates that European sea bass and meagre hatching rate exposed to launch simulation do not differ from their Earth rates. The hatching rate and the duration of embryogenesis were similar to those observed in commercial farming conditions without launcher vibration stress. On ground-based spaceflight preparation, a key challenge will be to identify the presence of the embryo at an early stage in order to select the most viable possible embryos. In this study, in the earliest stage, we were able to test for both species corresponding to $30 \%$ of the total embryo development. The biodiversity of fish involve different reproduction strategies and incubation periods. For a lunar flight, the period of incubation must be set to the trip duration ( 3 to 6 days depending on the flight plan). Hatching was planned to occur at the BLSS on the moon to avoid human intervention during the flight. Our results showed that European sea bass hatches $110 \mathrm{~h}$ after fertilization (4.5 days), which makes this species a potential candidate. Embryos could be placed in hypo physiology in the aim to delay hatching by 1 or 2 days (Soyano and Mushirobira 2018). However, if results of meagre eggs' mechanical resistance make it a potential candidate, the meagre hatches around $37 \mathrm{~h}$ after fertilization (1.5 days), so this species would be incompatible for transporting fish solely in their embryo phase. Future studies could investigate which aquaculture fish species would be most relevant to select according to their incubation period (up to $72 \mathrm{hpf}$ ). It is also important to consider logistics on the ground, such as boarding duration and the risk of launch window delays (due to aborted countdown, unfavourable weather, etc.) to ensure a margin of safety if there is a time lapse.

\section{Conclusion}

There are two substantive conclusions from our study. First of all, two aquaculture species have the capacity to hatch after a simulated spacecraft launch with a comparable ratio to current observations on Earth. Secondly, regardless of the embryonic life stage post third of the development, embryos are resistant to a qualifying test for a spaceflight. However, exposition during early stages post fertilization needs to be tested. These encouraging preliminary results confirm our intuition and hypothesis that aquatic forms can adapt to extreme environments such as outer space. So while our results indicate that the European sea bass and meagre could withstand launch conditions, future experiments have to investigate embryo and larva integrity in a space environment. Such a study should focus on fish embryos' resistance to hypergravity (launcher acceleration) and microgravity adaptation and the acceptable radiation dose for a normal larval development until the first feeding (around 5 days post hatching for European sea bass).

Over the last 50 years, a large amount of knowledge about fish aquaculture has been gathered, and this could be capitalized on as a tool for species selection using selective parameters regarding Moon flight constraints and Moon base fish farming feasibility. Research in this direction could make fish the first reared animal off-Earth in the aim of developing food autonomy in space.

Acknowledgements The Lunar Hatch programme and LAUVE project (2019-2020) are supported by Ifremer. The author would like to sincerely thank Véronique Ribière for her communications consulting expertise, her 
involvement and her valuable contributions in discussions around the project. A video of the experiment can be viewed at https://www.youtube.com/watch?v=Kwigd91ETmE\&feature=youtu.be. In memory of Gilles Futsch (1967-2016), the first supporter of the Lunar Hatch project.

Funding The experiments were auto-financed by the French institute for the exploration of the sea (Ifremer).

\section{Compliance with ethical standards}

Conflict of interest The authors declare that they have no conflict of interest.

Ethical approval All applicable international, national and institutional guidelines for the care and use of fish eggs were followed by the authors.

\section{References}

Arthur R (2009) Omega-3 sources. J Complement Med 8:28

Baiocco $\mathrm{G}$ et al (2018) A water-filled garment to protect astronauts during interplanetary missions tested on board the ISS. Life Sci Space Res 18:1-11. https://doi.org/10.1016/j.lssr.2018.04.002

Baranov (2009) The Biorisk experiment: 13-month exposure of resting forms of organism on the outer side of the Russian Segment of the International Space Station: preliminary results. Dokl Biol Sci 426:706-709

Barrett JE, Wells DC, Paulsen AQ, Conrad GW (2000) Embryonic quail eye development in microgravity. J Appl Physiol 88:1614-1622

Basilevsky AT, Abdrakhimov AM, Dorofeeva VA (2012) Water and other volatiles on the moon: a review. Sol Syst Res 46:89-107. https://doi.org/10.1134/s0038094612010017

Baumgarten V (1975) Effect of prolonged weightlessness on the swimming pattern of fish aboard Skylab 3. Aviat Sapce Environ Med 46:902-906

Blum V, Andriske M, Kreuzberg K, Schreibman MP (1995) Animal protein production modules in biological life support systems: novel combined aquaculture techniques based on the closed equilibrated biological aquatic system (CEBAS). Acta Astronautica 36:615-623. https://doi.org/10.1016/0094-5765(95)00150-6

Brown N, Eddy S, Plaud S (2011) Utilization of waste from a marine recirculating fish culture system as a feed source for the polychaete worm, Nereis virens. Aquaculture 322:177-183. https://doi.org/10.1016/j. aquaculture.2011.09.017

Chatani M et al (2015) Microgravity promotes osteoclast activity in medaka fish reared at the international space station. Sci Rep 5:14172. https://doi.org/10.1038/srep14172

Dallaire V, Lessard P, Vandenberg G, de la Noue J (2007) Effect of algal incorporation on growth, survival and carcass composition of rainbow trout (Oncorhynchus mykiss) fry. Bioresour Technol 98. https://doi. org/10.1016/j.biortech.2006.05.043

FAO (2018) The state of world fisheries and aquaculture 2018- Meeting the sustainable development goals. Food and Agriculture Organization of the United Nations. Rome, Italy, p 210. http:/www.fao.org/3/i9540 en/i9540en.pdf Licence: CC BY-NC-SA 3.0 IGO. Accessed 7 Sept 2020

Ghasemi Fard S, Wang FL, Sinclair AJ, Elliott G, Turchini GM (2019) How does high DHA fish oil affect health? A systematic review of evidence. Crit Rev Food Sci Nutr 59:1684-1727. https://doi.org/10.1080 /10408398.2018.1425978

Gonzales JM (2009) Aquaculture in bio-regenerative life support systems (BLSS): Considerations. Adv Space Res 43:1250-1255. https://doi.org/10.1016/j.asr.2009.01.034

Gonzales JM, Brown PB (2006) Nile tilapia Oreochromis niloticus as a food source in advanced life support systems: Initial considerations. Adv Space Res 38:1132-1137. https://doi.org/10.1016/j.asr.2005.11.002

Hanson J (1983) Ecology, Aquaculture And Space Colonies Proceedings OCEANS '83,San Francisco, CA, pp. 998-1001. https://doi.org/10.1109/OCEANS.1983.1152020

Ijiri K (1998) Development of space-fertilized eggs and formation of primordial germ cells in the embryos of Medaka fish. Adv Space Res 21:1155-1158

Ijiri K, Mizuno R, Eguchi H (2003) Use of an otolith-deficient mutant in studies of fish behavior in microgravity. In: Bruce LL, Ijiri K, Perbal G (eds) Space life sciences: gravitational biology: 2002, vol 32. Advances in Space Research-Series, vol 8. pp. 1501-1512. https://doi.org/10.1016/s0273-1177(03)00623-9

Johnson DS (2016) The first fish in orbit sprinkler/praxis. https://blogs.scientificamerican.com/guest-blog/thefirst-fish-in-orbit/. Accessed 7 Sept 2020 
Lane HW, Bourland C, Barrett A, Heer M, Smith SM (2013) The role of nutritional research in the success of human space flight. Adv Nutr 4:521-523. https://doi.org/10.3945/an.113.004101

Leys N, Baatout S, Rosier C, Dams A, s'Heeren C, Wattiez R, Mergeay M (2009) The response of Cupriavidus metallidurans $\mathrm{CH} 34$ to spaceflight in the international space station Antonie Van Leeuwenhoek. Int J Gen Mol Microbiol 96:227-245. https://doi.org/10.1007/s10482-009-9360-5

Li M et al (2019) Bioremediation of fishpond effluent and production of microalgae for an oyster farm in an innovative recirculating integrated multi-trophic aquaculture system. Aquaculture 504:314-325. https://oi. org/10.1016/j.aquaculture.2019.02.013

Mitrofanov IG, Sanin AB, Litvak ML (2016) Water in the moon's polar areas: results of LEND neutron telescope mapping. Dokl Phys 61:98-101. https://doi.org/10.1134/s1028335816020117

Mladineo I, Bocina I, Przybyla C, Fievet J, Blancheton JP (2010) Fish growth and health aspects of sea bass (Dicentrarchus labrax) reared in standard vs. high rate algal pond recirculation systems. Aquat Living Resour 23:217-224. https://doi.org/10.1051/alr/2010013

Mylonas CC, Mitrizakis N, Castaldo CA, Cervino CP, Papadaki M, Sigelaki I (2013) Reproduction of hatcheryproduced meagre Argyrosomus regius in captivity II. Hormonal induction of spawning and monitoring of spawning kinetics, egg production and egg quality. Aquaculture 414:318-327. https://doi.org/10.1016/j. aquaculture.2013.09.008

Niederwieser T, Kociolek P, Klaus D (2018a) A review of algal research in space. Acta Astronautica 146:359367. https://doi.org/10.1016/j.actaastro.2018.03.026

Niederwieser T, Kociolek P, Klaus D (2018b) ) Life Sci Space Res 16:8-17. https://oi.org/10.1016/j. lssr.2017.10.002

Nurge MA (2012) In situ dielectric spectroscopy for water detection on the lunar surface. Planet Space Sci 65: 76-82. https://doi.org/10.1016/j.pss.2012.01.010

Poughon L, Farges B, Dussap CG, Godia F, Lasseur C (2009) Simulation of the MELiSSA closed loop system as a tool to define its integration strategy. Adv Space Res 44:1392-1403. https://doi.org/10.1016/j. asr.2009.07.021

Poulet L, Fontaine JP, Dussap CG (2016) Plant's response to space environment: a comprehensive review including mechanistic modelling for future space gardeners. Bot Lett 163:337-347. https://doi.org/10.1080 /23818107.2016.1194228

Przybyla C, Fievet J, Callier M, Blancheton J-P (2014) Effect of dietary water content on European sea bass (Dicentrarchus labrax) growth and disease resistance. Aquat Living Resour 27:73-81. https://doi. org/10.1051/alr/2014007

Quinton R (1912) L'eau de mer, milieu organique vol Deuxième édition. Masson et Cie. Editeurs, Paris

Saavedra M et al. (2016) Different dietary protein levels affect meagre (Argyrosomus regius) larval survival and muscle cellularity Aquaculture 450:89-94. https://doi.org/10.1016/j.aquaculture.2015.07.004

Salisbury FB, Clark MAZ (1996) Suggestions for crops grown in controlled ecological life-support systems, based on attractive vegetarian diets. In: MacElroy RD, Kreuzberg K, Nielsen S, Tibbits TW (eds) Natural and artificial ecosystems, vol 18. Advances in Space Research-Series, vol 4/5. pp 33-39. https://doi. org/10.1016/0273-1177(95)00859-d

Scapigliati G, Carcupino M, Taddei AR, Mazzini M (1994) Characterization of the main egg envelope proteins of the sea bass (Dicentrarchus labrax L (teleostea serraniidae) Mol Reprod Dev 38:48-53. https://doi. org/10.1002/mrd.1080380109

Siegler M, Paige D, Williams JP, Bills B (2015) Evolution of lunar polar ice stability. Icarus 255:78-87. https://doi.org/10.1016/j.icarus.2014.09.037

Soyano K, Mushirobira Y (2018) The mechanism of low-temperature tolerance in fish. In: IwayaInoue M, Sakurai M, Uemura M (eds) Survival strategies in extreme cold and desiccation: adaptation mechanisms and their applications, Advances in Experimental Medicine and Biology, vol 1081, pp 149-164. https://oi. org/10.1007/978-981-13-1244-1_9

Stein TP, Blanc S (2011) Does protein supplementation prevent muscle disuse atrophy and loss of strength? Crit Rev Food Sci Nutr 51:828-834. https://doi.org/10.1080/10408398.2010.482679

Tacon AGJ, Metian M (2008) Global overview on the use of fish meal and fish oil in industrially compounded aquafeeds: trends and future prospects. Aquaculture 285:146-158. https://doi.org/10.1016/j. aquaculture.2008.08.015

Tulli F, Zittelli GC, Giorgi G, Poli BM, Tibaldi E, Tredici MR (2012) Effect of the inclusion of dried Tetraselmis suecica on growth, feed utilization, and fillet composition of European sea bass juveniles fed organic diets. J Aquat Food Product Technol 21:188-197. https://doi.org/10.1080/10498850.2012.664803

Vuolo $\mathrm{M}$ et al (2017) Exploring innovative radiation shielding approaches in space: a material and design study for a wearable radiation protection spacesuit. Life Sci Space Res 15:69-78. https://doi.org/10.1016/j. lssr.2017.08.003 
Zabel P, Bamsey M, Schubert D, Tajmar M (2016) Review and analysis of over 40 years of space plant growth systems. Life Sci Space Res 10:1-16. https://doi.org/10.1016/j.lssr.2016.06.004

Zuidhof MJ, Schneider BL, Carney VL, Korver DR, Robinson FE (2014) Growth, efficiency, and yield of commercial broilers from 1957, 1978, and 2005. Poult Sci 93:2970-2982. https://doi.org/10.3382/ps.201404291 